\title{
BMJ Open Providing routine chronic disease preventive care in community substance use services: a pilot study of a multistrategic clinical practice change intervention
}

\author{
Danika Tremain, ${ }^{1,2,3}$ Megan Freund, 2,3 Paula Wye, ${ }^{3,4}$ Jenny Bowman, ${ }^{3,4}$ \\ Luke Wolfenden, ${ }^{1,2,3}$ Adrian Dunlop, ${ }^{2,5,6}$ Kate Bartlem, ${ }^{1,3,4}$ \\ Christophe Lecathelinais, ${ }^{1,2,3}$ John Wiggers ${ }^{1,2,3}$
}

To cite: Tremain D, Freund M, Wye $\mathrm{P}$, et al. Providing routine chronic disease preventive care in community substance use services: a pilot study of a multistrategic clinical practice change intervention. BMJ Open 2018:8:e020042. doi:10.1136/ bmjopen-2017-020042

- Prepublication history for this paper is available online. To view these files, please visit the journal online (http://dx.doi. org/10.1136/bmjopen-2017020042).

Received 18 0ctober 2017 Revised 29 March 2018 Accepted 25 June 2018

\section{Check for updates}

(C) Author(s) (or their employer(s)) 2018. Re-use permitted under CC BY-NC. No commercial re-use. See rights and permissions. Published by BMJ.

For numbered affiliations see end of article.

\section{Correspondence to}

Ms. Danika Tremain;

danika.tremain@hnehealth.nsw. gov.au

\section{ABSTRACT}

Objectives To evaluate the potential effectiveness of a practice change intervention in increasing preventive care provision in community-based substance use treatment services. In addition, client and clinician acceptability of care were examined.

Design A pre-post trial conducted from May 2012 to May 2014.

Setting Public community-based substance use treatment services $(n=15)$ in one health district in New South Wales (NSW), Australia.

Participants Surveys were completed by 226 clients and 54 clinicians at baseline and 189 clients and 46 clinicians at follow-up.

Interventions A 12-month multistrategic clinician practice change intervention that aimed to increase the provision of preventive care for smoking, insufficient fruit and/or vegetable consumption and insufficient physical activity.

Primary and secondary outcome measures Client and clinician reported provision of assessment, brief advice and referral for three modifiable health risk behaviours: smoking, insufficient fruit and/or vegetable consumption and insufficient physical activity. Clinician-reported optimal care was defined as providing care to $80 \%$ of clients or more. Client acceptability and clinician attitudes towards preventive care were assessed at follow-up.

Results Increases in client reported care were observed for insufficient fruit and/or vegetable consumption including: assessment ( $24 \%$ vs $54 \%, p<0.001)$, brief advice ( $26 \%$ vs $46 \%, p<0.001)$, and clinicians speaking about $(10 \%$ vs $31 \%, p<0.001)$ and arranging a referral ( $1 \%$ vs $8 \%, p=0.006)$ to telephone helplines. Clinician reported optimal care delivery increased for: assessment of insufficient fruit and/or vegetable consumption ( $22 \%$ vs $63 \%, p<0.001$ ) and speaking about telephone helplines for each of the three health risk behaviours. Overall, clients and clinicians held favourable views regarding preventive care.

Conclusion This study reported increases in preventive care for insufficient fruit and/or vegetable consumption; however, minimal increases were observed for smoking
Strengths and limitations of this study

- The first study to evaluate the effectiveness of a multistrategic clinical practice intervention on the provision of preventive care to community-based substance use clients for multiple health risk behaviours.

- A strength of this study is the use of multiple data collection points with both client and clinician report.

- The study is limited by the pre-post design; however, this design was considered appropriate for a preliminary examination of the potential effectiveness of a clinician practice change intervention.

- The use of participant self-report of care provision may result in overestimates of care provision.

or insufficient physical activity. Further investigation of the barriers to preventive care delivery in community substance use settings is needed.

Trialregistration number ACTRN12614000469617.

\section{BACKGROUND}

People with substance use problems experience a life expectancy of up to 25 years less than the general population. ${ }^{1-3}$ A proportion of this reduced life expectancy is attributed to high rates of preventable chronic illness such as cardiovascular disease, diabetes and cancer. ${ }^{14-7}$ Contributing to such illness is a high prevalence of modifiable health risk behaviours $^{89}$ such as smoking, insufficient fruit and/or vegetable consumption and insufficient physical activity. ${ }^{10-14}$

Clinical practice guidelines recommend that preventive care should be delivered routinely by health service providers to reduce the prevalence of modifiable health risk behaviours. ${ }^{15-21}$ Although preventive 
care practice guidelines are not specific to substance use treatment settings, there is increasing research and service delivery interest in enhancing the delivery of such care in this setting. ${ }^{22}{ }^{23}$ Substance use treatment services represent an opportunity for the provision of such care as they often involve multidisciplinary care teams who are skilled in behaviour change and incorporate multiple treatment episodes. ${ }^{23-26}$ Despite this, the provision of preventive care in substance use clinical settings occurs at suboptimal levels. ${ }^{27-30}$ For example, a study within 111 US community substance treatment programs found that $66 \%$ of counsellors routinely asked patients if they smoked, $44 \%$ advised smokers to quit and $30 \%$ provided patients with a quit-line number. ${ }^{30}$ The only study identified that reported the prevalence of care for insufficient nutrition or physical activity found suboptimal levels of client reported assessment (22\% and $51 \%$ ), brief advice (25\% and $49 \%)$ and helpline referral (1\% and 2\%), respectively, across 15 Australian substance use treatment services. ${ }^{29}$

Only one study could be identified that examined the effectiveness of an intervention to increase preventive care delivery in substance use settings. Using a pre-post study design, Guydish et $a l^{31}$ examined the effect of a 6-month practice change intervention on the provision of smoking cessation care in three US residential substance use services. The practice change strategies included consultation, leadership and support, policy development and staff training. Clients $(n=150)$ reported an increase in the receipt of education, pamphlets, pharmacotherapy, counselling and the provision of support groups. An increase in favourable attitudes towards smoking cessation care was reported by both clients and staff $(n=143)$. Although such results suggest that practice change interventions may increase preventive care delivery, the study was limited to a single health risk behaviour and residential settings.

Given the limited extent of intervention research, a study was undertaken to assess the potential effectiveness and acceptability of a multistrategic, evidence-based, practice change intervention to increase the provision of preventive care for smoking, insufficient fruit and/or vegetable consumption and insufficient physical activity in community substance use treatment settings.

\section{METHODS}

\section{Study design and setting}

A pre-post trial was conducted within public community-based substance use treatment services in one health district in New South Wales (NSW), Australia. Clients are referred (including self-referral) to the free government-funded services.

\section{Participants and recruitment}

Community-based substance use treatment services

Community-based substance use treatment services were chosen as approximately $90 \%$ of Australian substance use treatment occurs within outpatient or community services, with the remaining occurring in residential or inpatient settings. ${ }^{32} 33$ In Australia, publicly funded outpatient and community services are conducted outside of inpatient or residential settings. In the context of this study, outpatient settings are generally provided by hospitals, whereas community health services are under the remit of community health. Services were ineligible to participate if they were: residential, inpatient hospital or intake-only services; primarily cared for clients under 18 years; or only provided care in a group setting. All eligible public community-based services $(n=15)$ in the study region were invited to participate. The services included those providing counselling and management, outpatient withdrawal, stimulant and cannabis specific treatment, and court diversion programs.

\section{Clients}

Clients were eligible for data collection if they: were $\geq 18$ years of age; had a face-to-face appointment within the previous 2weeks; had not previously completed the survey; and had not been identified as inappropriate for contact by their clinician (eg, were seeing a confidential service and family members or others may become aware of their treatment through the client participating in the data collection procedures). Additional eligibility criteria included English proficiency and mental and physical capability of completing the study procedures (determined by interviewers on client contact).

Each week throughout the baseline and follow-up data collection periods, 30 eligible clients were randomly selected from the substance use services' electronic medical record system using SAS V.9.3 software. ${ }^{34}$ Selected clients were mailed a study information letter.

\section{Clinicians}

All clinicians received the intervention. Clinicians were eligible to participate in data collection if they: had $\geq 10$ face-to-face appointments with adult clients within the previous 2 months; had been employed by the service for at least 3 months; and were not on leave. Eligible clinicians were mailed an information letter.

\section{INTERVENTION}

\section{Model of preventive care}

The preventive care model was based on the 2As and an $\mathrm{R}$ model (ask, advise and refer).$^{26}$ This model has been recommended as an effective way to address modifiable health risk behaviours while also acknowledging barriers to care provision, including competing clinical priorities and brevity of clinician contact. ${ }^{192635}$ Clinicians were required to assess all clients every 6 months (as indicated by the clients' medical records) regarding their smoking, fruit and vegetable consumption and physical activity. Assessment was recommended to occur every 6 months to emphasise the importance of routine provision of preventive care. Assessment questions aligned with, and client risk status was determined according to, the Australian 
National Guidelines. ${ }^{36-39}$ For clients who were identified as 'at risk', clinicians were required to provide brief advice and referral to further support. Referral options were free government telephone coaching services: the NSW Quitline and the NSW Get Healthy Information and Coaching Service; general practitioners (GPs) or Aboriginal Medical Services (AMS); and other local care delivery providers (eg, dietitians and physiotherapists). Telephone helplines have been shown to be effective in the general population ${ }^{404}$ and for people with substance use problems. ${ }^{35}$ In addition, such services provide free and readily accessible support, which may address barriers to treatment for people with substance use problems, such as transportation and cost. ${ }^{42}$

\section{Clinical practice change intervention}

The following evidence-based ${ }^{43-46}$ practice change strategies were implemented simultaneously in all participating services over 12 months:

1. Leadership and consensus ${ }^{46}$ : the preventive care model was formalised through a health service-wide policy. Clinical teams and management were consulted prior to and during the implementation of the intervention, at least once a fortnight. Senior health district management were consulted to confirm their continued support for the intervention and to reach agreement on key performance indicators.

2. Enabling systems and procedures: the existing electronic medical record system was modified to include a health risk behaviour assessment tool to support the standardised provision and recording of care. The tool recorded the assessment of client health risk behaviours (eg, Have you ever been a smoker?) and the client responses. The tool provided suggested wording regarding the provision of brief advice in line with Australian national guidelines ${ }^{36-39}$ (eg, The best thing you can do for your health is to stop smoking) and suggested referral services in an effort to standardise and prompt care delivery.

3. Clinician and manager training ${ }^{43}$ : clinicians and service managers were invited to face-to-face training conducted by a support officer for approximately 2 hours and were required to complete six competency-based online modules (approximately 1.5 hours). The training and online modules covered the recommended model of preventive care, providing and recording care, and cultural appropriateness. All eligible clinicians and service managers had attended face-to-face and/or online training at the completion of the intervention.

4. Implementation support: a support officer with health promotion and clinical practice change experience was allocated to each site, providing the initial face-toface training, a minimum of one visit per month and fortnightly phone or email contact with managers. The support officer provided training and discussed project progress, any problems or concerns and potential solutions to overcome such concerns. Managers were encouraged to proactively contact the support officers with concerns or problems.

5. Monitoring and feedback ${ }^{44}$ : each month, service-specific feedback reports regarding the prevalence of preventive care were generated from the electronic medical records and emailed to managers. Support officers discussed the service's performance and plans for increasing care provision with managers. Managers were encouraged to share the feedback reports with their staff.

6. Provision of clinical practice change resources ${ }^{45}$ : clinicians and managers were provided with resources including: a guide to providing and recording preventive care in the medical records system; copies of a paper assessment tool to be used when a computer was not accessible; flip charts; client handouts; helpline fax referral forms; posters; and monthly newsletters. An email helpline and internet information site that included printable versions of all resources were also provided.

\section{DATA COLLECTION PROCEDURES}

The primary method of data collection was client and clinician computer-assisted telephone interview (CATI) administered by trained interviewers.

\section{Clients}

Client surveys were undertaken prior to intervention commencement (baseline: May-October 2012) and immediately following intervention completion (follow-up: November 2013-May 2014). Clients were contacted 2 weeks after receiving the information letter to complete the survey (approximately $25 \mathrm{~min}$ ).

\section{Clinicians}

Clinician surveys were undertaken prior to intervention commencement (baseline: October-November 2012) and immediately following the intervention completion (follow-up: November 2013-February 2014). Clinicians were contacted 4 weeks after receiving the information letter to complete the survey (approximately $30 \mathrm{~min}$ ).

\section{PATIENT AND PUBLIC INVOLVEMENT}

The focus of the study was increasing the provision of preventive care by clinicians. Clinicians were involved in the development of the study. Patients were not included in the development of the research question, outcome measures, data collection procedures, recruitment or conduct of the study. The results will not be disseminated to patients.

\section{MEASURES}

\section{Participant characteristics and health risk behaviours}

Client age, gender, postcode and number of appointments with the service within the previous 12 months were obtained from electronic medical records. During 
the CATI, clients were asked their: employment status, Aboriginal and/or Torres Strait Islander status, marital status, highest level of education attained and any mental or physical conditions for which they were receiving medical attention. Using items previously used to assess prevalence of health behaviour, ${ }^{47-49}$ clients were asked to report whether they were a smoker of any tobacco products, ${ }^{47}$ how many serves of vegetables and fruit they usually consumed each day ${ }^{48}$ and how many days a week they usually undertook $30 \mathrm{~min}$ or more of physical activity. ${ }^{49}$ Following Australian National Guidelines, ${ }^{36-39}$ participants were defined as being at risk if they: smoked any tobacco products, ${ }^{39}$ consumed less than two serves of fruit and/or five serves of vegetables per day ${ }^{37}$ or participated in less than $30 \mathrm{~min}$ of physical activity at least five times a week. ${ }^{38}$

During the clinician CATI, clinicians were asked to report their age, Aboriginal and/or Torres Strait Islander status, years working in community health and their current employment status. Clinician gender, discipline and service team were extracted from the electronic records system.

\section{Client reported provision of preventive care}

For assessment, clients were asked if a clinician asked about their smoking status, fruit and/or vegetable consumption and levels of physical activity (yes, no or don't know). For provision of brief advice, clients classified as 'at risk' were asked if a clinician advised them to quit smoking or use nicotine replacement therapy, to increase their fruit and/ or vegetable consumption or to participate in more physical activity (yes, no or don't know). For referral, 'at risk' clients were asked if a clinician spoke to them about, or offered them a referral (yes, no or don't know) to the NSW Quitline (for smoking) ${ }^{50}$ or the Get Healthy Information and Coaching Service (for physical activity and nutrition) ${ }^{51}$ Clients were also asked if a clinician recommended any other supports (eg, GP, AMS, dietitian, internet websites, physical activity classes and physiotherapist) (yes, no or don't know).

\section{Clinician reported provision of preventive care}

On a scale of $0 \%-100 \%$ or 'don't know', ${ }^{52} 53$ clinicians were asked to report the proportion of clients in the previous 2 months they asked about each of the health risk behaviours (assessment), the proportion of 'at risk' clients for which they advised to modify their risky health behaviour(s) (brief advice) and the proportion of 'at risk' clients they provided with referral options. Referral measures were the same as those for client report.

\section{Client reported acceptability of preventive care provision}

At follow-up, clients were asked to indicate their level of agreement (strongly agree, agree, unsure, disagree or strongly disagree) with three statements for each behavioural risk regarding: the acceptability of substance use treatment clinicians asking about their health behaviours, and for clients at risk, providing brief advice and arranging a referral to further support.

\section{Clinician reported attitudes regarding the provision of preventive care}

At follow-up, clinicians were asked to indicate their level of agreement (strongly agree, agree, unsure, disagree, strongly disagree or refused) with 13 statements within three attitudinal domains: perceived role in the provision of preventive care; self-efficacy in providing preventive care; and perception of client interest in modifying health risk behaviours. ${ }^{54}$

\section{STATISTICAL POWER \\ Client report}

Of the 30 clients selected each week in the baseline and follow-up periods, it was estimated that $75 \%$ would be eligible for contact $(n=23), 60 \%$ of eligible clients would be contactable $(\mathrm{n}=14)$ and of those contacted $70 \%$ would complete the survey $(n=9) .{ }^{55}$ Therefore, it was expected that 234 clients would participate in the CATI at baseline and at follow-up. Assuming a baseline prevalence of care of $23 \%,{ }^{29}$ it was estimated the study would have $80 \%$ power to detect an increase in assessment of $15 \%$ from baseline to follow-up $(\alpha=0.01)$. Using the least prevalent health risk behaviour (physical activity; $31 \%{ }^{56}$ ) and an assumed prevalence of care at baseline of $25 \%,{ }^{29}$ the study was estimated to have $80 \%$ power to detect an increase of $27 \%$ in the provision of brief advice and offer of referral.

\section{STATISTICAL ANALYSIS}

Analyses were undertaken using SAS V.9.3. Client residential postcodes were used to determine disadvantage (Socio-Economic Indexes for Areas (SEIFA)) and remoteness (Access/Remoteness Index of Australia). SEIFA codes were collapsed into low, medium and high disadvantage, and geographic location collapsed into major cities versus regional/remote towns. ${ }^{57}{ }^{58}$ Client reported provision of each element of care was dichotomised into 'yes' and 'no' (no or don't know) responses. Client reported acceptability of care and clinician reported attitudes regarding preventive care were dichotomised into 'agree' (strongly agree oragree) and 'disagree' (unsure, disagree or strongly disagree).

An additional variable, provision of "care for all risks, ${ }^{52} 53$ was created for the proportion of clients who: were assessed for all risk behaviours (assessment); given brief advice for all their risk behaviours (brief advice); and offered a referral for all their risk behaviours (offer to arrange referral to telephone helplines).

Based on recommendations of clinical guidelines ${ }^{19-21}$ and consistent with prior studies, ${ }^{52} 53$ clinician reported optimal care was defined as care provided to $80 \%$ or more of clients and was considered an appropriate benchmark for care provision. In addition, an overall 'optimal care' variable was created for each element of care (assessment, 
brief advice, spoke about telephone service, arrange referral to telephone service, advise GP/AMS and advise other support) for each risk behaviour separately and for all behaviours combined. ${ }^{52} 5359$

$\chi^{2}$ analyses were used to compare baseline and follow-up characteristics of clients and clinicians and characteristics between participants and non-participants.

\section{Provision of preventive care}

For client report, logistic regression was used to examine change in care provision between baseline and follow-up. Analyses were undertaken for each element of care for the three health risks behaviours individually and for 'care for all risks' (20 models). All models were adjusted for age, gender, service type and number of appointments.

For clinician report, $\chi^{2}$ analyses were used to compare the prevalence of 'optimal' preventive care at baseline and follow-up for each care element for each health risk behaviour individually and for all health risk behaviours combined (24 outcomes).

A Bonferroni adjusted significance level of $p<0.003$ was used for all care provision analyses.

\section{RESULTS}

Client sample

Of the 1132 clients randomly selected to participate in the surveys, $306(27 \%)$ were unable to be contacted to complete the survey and $125(11 \%)$ were ineligible. Of the 701 contactable and eligible clients, 415 (59\%) agreed to participate. Compared with non-participants, participants were less likely to be of Aboriginal and/ or Torres Strait Islander origin (28\% vs $15 \%, \mathrm{p}<0.001)$ or be under 40 years of age $(67 \%$ vs $51 \%, \mathrm{p}<0.001)$ and more likely to have had only one service appointment (58\% vs $64 \%, \mathrm{p}<0.001)$. Compared with baseline, clients at follow-up were more likely to have completed a technical certificate, university or higher degree and to have had one service appointment (table 1).

\section{Clinician sample}

Of the 186 clinicians invited to participate in the surveys, $146(78 \%)$ were eligible of whom $100(68 \%)$ agreed to participate. Compared with baseline, participating clinicians at follow-up were more likely to work in their discipline for 10 years or more (table 2).

\section{Client reported provision of preventive care}

Provision of preventive care increased from baseline to follow-up for 6 out of 20 measures. Assessment of health behaviour risks increased for insufficient fruit and/or vegetable consumption (24\% vs $54 \%, \mathrm{p}<0.001$ ) and for all risks combined ( $18 \%$ vs $48 \%, \mathrm{p}<0.001)$. Brief advice increased for insufficient fruit and/or vegetable consumption ( $26 \%$ vs $46 \%, \mathrm{p}<0.001$ ) and all risks combined (26\% vs $44 \%, \mathrm{p}<0.001)$. Clinicians speaking about the helpline increased for insufficient fruit and/ or vegetable consumption $(10 \%$ vs $31 \%, \mathrm{p}<0.001)$ and for
Table 1 Client characteristics (baseline $n=226$, follow-up $\mathrm{n}=189$ )

\begin{tabular}{lccc}
\hline Characteristic & $\begin{array}{l}\text { Baseline } \\
\mathbf{n}(\%)\end{array}$ & $\begin{array}{l}\text { Follow-up } \\
\mathbf{n}(\%)\end{array}$ & P values \\
\hline Female & $70(31)$ & $52(28)$ & 0.44 \\
$\begin{array}{l}\text { Aboriginal and/or Torres Strait } \\
\text { Islander }\end{array}$ & $50(22)$ & $33(18)$ & 0.11 \\
$\begin{array}{l}\text { Age (years) } \\
18-34\end{array}$ & $89(39)$ & $67(35)$ & \\
\hline $35-54$ & $113(50)$ & $106(56)$ & \\
\hline $55+$ & $24(11)$ & $16(8)$ & \\
\hline $\begin{array}{l}\text { Employment status } \\
\quad \text { Employed }\end{array}$ & $65(29)$ & $72(38)$ & 0.44 \\
\hline $\begin{array}{l}\text { Not employed } \\
\text { Marital status }\end{array}$ & $161(71)$ & $117(62)$ & \\
\hline Living with partner & $158(70)$ & $123(65)$ & 0.29 \\
\hline $\begin{array}{l}\text { Not living with partner } \\
\text { Highest education level } \\
\text { completed }\end{array}$ & $68(30)$ & $66(35)$ & \\
\hline
\end{tabular}

\begin{tabular}{|c|c|c|c|}
\hline High school or less & $49(22)$ & $34(18)$ & \\
\hline Completed high school & $95(42)$ & $57(30)$ & \\
\hline $\begin{array}{l}\text { Technical certificate, } \\
\text { university degree or higher }\end{array}$ & $82(36)$ & $98(52)$ & \\
\hline Geographic location & & & 0.07 \\
\hline Major cities & $67(30)$ & $41(22)$ & \\
\hline Regional/remote & $159(70)$ & $148(78)$ & \\
\hline Index of disadvantage & & & 0.57 \\
\hline Low & $13(6)$ & $9(5)$ & \\
\hline Moderate & $104(46)$ & $94(5)$ & \\
\hline High & $108(48)$ & $86(45)$ & \\
\hline Service type & & & 0.08 \\
\hline Counselling & $182(81)$ & $167(89)$ & \\
\hline Stimulant treatment & $14(6)$ & $7(4)$ & \\
\hline Court diversion & $29(13)$ & $14(7)$ & \\
\hline \multicolumn{4}{|l|}{ Times seen in the last 12 months } \\
\hline Mean (SD) & $3.4(5.1)$ & $1.6(1.5)$ & \\
\hline 1 & $106(47)$ & $131(69)$ & $<0.001$ \\
\hline $2-4$ & $80(35)$ & $52(28)$ & \\
\hline $5-11$ & $27(12)$ & $5(3)$ & \\
\hline $12+$ & $13(6)$ & $1(1)$ & \\
\hline \multicolumn{4}{|l|}{ Risk factor } \\
\hline Smoking & $174(77)$ & $129(68)$ & 0.04 \\
\hline $\begin{array}{l}\text { Insufficient fruit and/or } \\
\text { vegetable consumption }\end{array}$ & $196(87)$ & $150(79)$ & 0.03 \\
\hline Insufficient physical activity & $65(29)$ & 67 (36) & 0.15 \\
\hline
\end{tabular}

all risks combined ( $11 \%$ vs $28 \%, \mathrm{p}<0.001)$ (table 3 ). No increases were indicated any form of preventive care for smoking or insufficient physical activity.

\section{Clinician-reported provision of optimal preventive care}

Provision of optimal care increased from baseline to follow-up for 6 out of 24 measures including: assessment 


\begin{tabular}{|c|c|c|c|}
\hline Characteristic & $\begin{array}{l}\text { Baseline } \\
(n=54) n(\%)\end{array}$ & $\begin{array}{l}\text { Follow-up } \\
(n=46) n(\%)\end{array}$ & $\begin{array}{l}P \\
\text { values }\end{array}$ \\
\hline Female & $40(74)$ & $36(78)$ & 0.63 \\
\hline $\begin{array}{l}\text { Aboriginal and/or } \\
\text { Torres Strait Islander } \\
\text { origin }\end{array}$ & $7(13)$ & $2(4)$ & 0.12 \\
\hline Age (years) & & & 0.79 \\
\hline $20-39$ & $12(22)$ & $11(24)$ & \\
\hline $40+$ & $42(78)$ & $34(76)$ & \\
\hline $\begin{array}{l}\text { Years in community } \\
\text { health }\end{array}$ & & & 0.87 \\
\hline$<2$ & 7 (13) & $6(13)$ & \\
\hline $3-9$ & $14(26)$ & $14(30)$ & \\
\hline $10+$ & $33(61)$ & $26(57)$ & \\
\hline Discipline & & & 0.77 \\
\hline Nurse & $25(46)$ & $22(48)$ & \\
\hline $\begin{array}{l}\text { Psychologist/ } \\
\text { counsellor/ } \\
\text { social worker }\end{array}$ & $23(43)$ & $17(37)$ & \\
\hline Other & $6(11)$ & $7(15)$ & \\
\hline Years in discipline & & & $<0.001$ \\
\hline$<2$ & $16(30)$ & $2(4)$ & \\
\hline $3-4$ & $17(32)$ & $10(22)$ & \\
\hline $10+$ & $21(39)$ & $34(74)$ & \\
\hline Service team & & & 0.52 \\
\hline Counselling & $18(33)$ & 18 (39) & \\
\hline Pharmacotherapy & $13(24)$ & $13(28)$ & \\
\hline $\begin{array}{l}\text { Stimulant } \\
\text { treatment }\end{array}$ & $15(28)$ & $7(15)$ & \\
\hline $\begin{array}{l}\text { Court diversion } \\
\text { programs }\end{array}$ & $8(15)$ & $8(17)$ & \\
\hline Employment status & & & 0.58 \\
\hline Full time & $37(69)$ & $35(76)$ & \\
\hline Part time & $14(26)$ & $10(22)$ & \\
\hline Casual & $3(6)$ & $1(2)$ & \\
\hline
\end{tabular}

of insufficient fruit and/or vegetable consumption $(22 \%$ vs $63 \%, \mathrm{p}<0.001)$ and all risks combined $(15 \%$ vs $61 \%, \mathrm{p}<0.001)$, and talking to clients about the telephone helplines for smoking ( $41 \%$ vs $74 \%, \mathrm{p}=0.003$ ), insufficient fruit and/or vegetable consumption $(11 \% \mathrm{vs}$ $57 \%, \mathrm{p}<0.001$ ), insufficient physical activity (9\% vs $41 \%$, $\mathrm{p}<0.001)$ and all risks combined (6\% vs $30 \%, \mathrm{p}<0.001)$ (table 4).

\section{Client acceptability of preventive care}

Across all risk behaviours and each element of care, the majority of clients agreed that such care was acceptable (85\%-99\%).
Clinician-reported attitudes regarding the provision of preventive care

Overall, the majority of clinicians reported high levels of agreement with the attitudinal statements $(>75 \%$ agreement with 9 of 12 statements). The least supported statements were from each of the three attitudinal domains: providing preventive care leaves time to undertake acute care $(65 \%)$; clients will change all their health behaviours due to the care provided (57\%); and clients were interested in changing their health behaviours (39\%) (table 5).

\section{DISCUSSION}

This study investigated the potential effectiveness of a clinical practice change intervention in increasing clinician provision of preventive care for multiple health risk behaviours within community-based substance use services. Across four behaviours, three elements of preventive care and client and clinician report, significant increases in care provision were observed for 12 of a total of 44 outcomes assessed, primarily for insufficient fruit and vegetable consumption. The increased care provision found for such outcomes suggests the intervention has the potential to increase preventive care delivery.

The greatest intervention effect was indicated for insufficient fruit and/or vegetable consumption for both client and clinician report and suggests clinicians can be assisted to provide preventive care addressing such risks within community substance use treatment settings. The importance of a strategy to address insufficient fruit and/ or vegetable consumption is emphasised by the significant health burden associated with such risks, ${ }^{6061}$ the high prevalence of such risks within substance use treatment clients ${ }^{56}$ and the low levels of care being provided at baseline.

The only increase in provision of smoking-related care was found for speaking about the Quitline to clients who were smokers, as reported by clinicians but not clients. Provision of assessment and brief advice for smoking may not have increased due to the high levels of provision at baseline: $87 \%-90 \%$ and $77 \%-80 \%$, respectively. Such high levels of care may be due to clinicians feeling more confident to address smoking given it is the risk behaviour most closely aligned with substance use treatment services. ${ }^{12}$

Increases in provision of care for insufficient physical activity were only observed for clinician reported speaking about the Get Healthy Information and Coaching helpline. The prevalence of insufficient physical activity compared with the other health risk behaviours was lower and therefore addressing such risk may not be perceived as a treatment priority. In addition, although clinicians may recognise the importance of assessing physical activity for all clients, to overcome barriers such as competing clinical priorities, clinicians may target high-risk clients for care provision around insufficient physical activity. ${ }^{62}$

Little intervention impact was indicated for referral to further specialist behaviour change support across all 
Table 3 Comparison of client reported provision of preventive care between baseline and follow-up (baseline: $n=226$, followup: $n=189$ )

\begin{tabular}{|c|c|c|c|c|}
\hline Outcome & $\begin{array}{l}\text { Baseline } \\
\text { n (\%) }\end{array}$ & $\begin{array}{l}\text { Follow-up } \\
\mathrm{n}(\%)\end{array}$ & OR $(95 \% \mathrm{Cl})$ & $P$ values \\
\hline \multicolumn{5}{|l|}{ Assessment } \\
\hline Smoking & $202(90)$ & $176(93)$ & $1.6(0.7$ to 3.2$)$ & 0.24 \\
\hline Insufficient fruit and/or vegetable consumption & $55(24)$ & $102(54)$ & 3.4 (2.2 to 5.3$)$ & $<0.001$ \\
\hline Insufficient physical activity & $128(57)$ & $122(65)$ & 1.5 (1.0 to 2.3$)$ & 0.07 \\
\hline All risks & $42(19)$ & $90(48)$ & 3.8 (2.4 to 6.0$)$ & $<0.001$ \\
\hline \multicolumn{5}{|l|}{ Brief advice $^{*}$} \\
\hline Smoking & $134(77)$ & $88(68)$ & 0.6 (0.3 to 1.0$)$ & 0.05 \\
\hline Insufficient fruit and/or vegetable consumption & $50(26)$ & $69(46)$ & 2.5 (1.6 to 4.1$)$ & $<0.001$ \\
\hline Insufficient physical activity & $35(54)$ & $40(60)$ & 1.7 (0.9 to 3.9$)$ & 0.17 \\
\hline All risks & $57(26)$ & $79(44)$ & 2.4 (1.5 to 3.8$)$ & $<0.001$ \\
\hline \multicolumn{5}{|l|}{ Spoke about telephone helplines* } \\
\hline Smoking (Quitline) & $87(50)$ & $64(50)$ & $1.0(0.6$ to 1.6$)$ & 0.96 \\
\hline $\begin{array}{l}\text { Insufficient fruit and/or vegetable consumption } \\
\text { (Get Healthy) }\end{array}$ & $19(10)$ & $47(31)$ & 4.1 (2.2 to 7.7$)$ & $<0.001$ \\
\hline Insufficient physical activity (Get Healthy) & $6(9)$ & $17(25)$ & $2.4(0.8$ to 7.0$)$ & 0.11 \\
\hline All risks & $24(11)$ & $50(28)$ & $3.2(1.8$ to 5.6$)$ & $<0.001$ \\
\hline \multicolumn{5}{|l|}{ Offered to arrange a referral to telephone helplines ${ }^{\star}$} \\
\hline Smoking (Quitline) & $11(6)$ & $13(10)$ & 2.7 (1.0 to 7.2$)$ & 0.05 \\
\hline $\begin{array}{l}\text { Insufficient fruit and/or vegetable consumption } \\
\text { (Get Healthy) }\end{array}$ & $1(1)$ & $12(8)$ & $18.4(2.3$ to 149.8$)$ & 0.006 \\
\hline Insufficient physical activity (Get Healthy) & $2(3)$ & $3(5)$ & $1.4(0.2$ to 9.8$)$ & 0.75 \\
\hline All risks & $2(1)$ & $9(5)$ & 9.1 (1.5 to 56.7$)$ & 0.02 \\
\hline \multicolumn{5}{|l|}{ Recommend other support (includes GP/AMS) ${ }^{\star} \dagger$} \\
\hline Smoking & $47(27)$ & $31(24)$ & 0.9 (0.5 to 1.7$)$ & 0.85 \\
\hline Insufficient fruit and/or vegetable consumption & $19(10)$ & $16(11)$ & 3.5 (1.2 to 9.8$)$ & 0.94 \\
\hline Insufficient physical activity & $13(20)$ & $21(31)$ & $1.0(0.5$ to 2.1$)$ & 0.02 \\
\hline All risks & $11(5)$ & $15(8)$ & 1.7 (0.7 to 4.1$)$ & 0.20 \\
\hline
\end{tabular}

*Sample only include clients who had reported not meeting the guidelines for the relevant health risk behaviour. Smoking: baseline=174, follow-up=129; insufficient fruit and/or vegetable consumption: baseline=196, follow-up=150; insufficient physical activity: baseline=65, follow-up=67 (table 1).

†Other support included: GP, AMS dietitian, internet websites, physical activity classes and physiotherapist. AMS, Aboriginal Medical Service; GP, general practitioner.

behaviours and referral to the helplines remained low $(<10 \%)$. Low levels of arranging referral may be due to clients declining an offer of referral or clinicians delaying referral due to clients' acute substance use problems. ${ }^{63}$ However, given the high level of client acceptability regarding referral (85\%-95\%), other barriers to the routine referral of clients are likely.

One such potential barrier is clinician belief that clients are not interested in improving their health risk behaviours. Only $39 \%$ of clinicians reported their clients were interested in modifying their health behaviours. However, research indicates that substance use service clients are interested in quitting smoking $(67 \%-$ $69 \%),{ }^{1456}$ increasing fruit and/or vegetable consumption $(55 \%)^{56}$ and increasing physical activity $(67 \%-81 \%) .{ }^{1456}$
In addition, over a half of clinicians $(56 \%)$ believed that clients would change all their health risk behaviours due to the care provided. Such beliefs may be influenced by the clients' other presenting issues, such as legal or child protections problems or partner violence. ${ }^{64} \mathrm{~A}$ further barrier to preventive care delivery may be the lack of formal guidelines for preventive care that recognise the unique aspects of substance use treatment. ${ }^{65}$

The findings of this study should be considered in light of its strengths and limitations. A strength of this study is the use of both client and clinician report. Although there is no gold standard for measuring preventive care provision, ${ }^{66}$ multiple data collection methods can demonstrate consistent trends ${ }^{67}$ such as that found regarding fruit and/or vegetable consumption and 
Table 4 Clinician reported provision of 'optimal' care (provided to $>80 \%$ clients)

\begin{tabular}{|c|c|c|c|}
\hline Outcome & $\begin{array}{l}\text { Baseline } \\
n=54 \\
n(\%)\end{array}$ & $\begin{array}{l}\text { Follow-up } \\
n=46 \\
n(\%)\end{array}$ & $P$ values \\
\hline \multicolumn{4}{|l|}{ Assessment } \\
\hline Smoking & $47(87)$ & $46(100)$ & 0.01 \\
\hline Insufficient fruit and/or vegetable consumption & $12(22)$ & $29(63)$ & $<0.001$ \\
\hline Insufficient physical activity & $24(44)$ & $32(70)$ & 0.01 \\
\hline All risks & $8(15)$ & $28(61)$ & $<0.001$ \\
\hline \multicolumn{4}{|l|}{ Brief advice } \\
\hline Smoking (quit/NRT) & $43(80)$ & $40(87)$ & 0.33 \\
\hline Insufficient fruit and/or vegetable consumption & $26(48)$ & $31(67)$ & 0.05 \\
\hline Insufficient physical activity & $28(52)$ & $24(52)$ & 0.97 \\
\hline All risks & $33(61)$ & $27(59)$ & 0.81 \\
\hline \multicolumn{4}{|l|}{$\begin{array}{l}\text { Referral } \\
\text { Spoke about telephone service }\end{array}$} \\
\hline Smoking (Quitline) & $22(41)$ & $34(74)$ & $<0.001$ \\
\hline Insufficient fruit and/or vegetable consumption (Get Healthy) & $6(11)$ & $26(57)$ & $<0.001$ \\
\hline Insufficient physical activity (Get Healthy) & $5(9)$ & $19(41)$ & $<0.001$ \\
\hline All risks & $3(6)$ & $14(30)$ & $<0.001$ \\
\hline \multicolumn{4}{|l|}{ Arranged referral to telephone service } \\
\hline Smoking (Quitline) & $0(0)$ & $2(4)$ & 0.12 \\
\hline Insufficient fruit and/or vegetable consumption (Get Healthy) & $2(4)$ & $1(2)$ & 0.65 \\
\hline Insufficient physical activity (Get Healthy) & $1(2)$ & $1(2)$ & 0.91 \\
\hline All risks & $0(0)$ & $1(2)$ & 0.28 \\
\hline \multicolumn{4}{|l|}{ Advised GP/AMS } \\
\hline Smoking & $21(39)$ & $18(39)$ & 0.98 \\
\hline Insufficient fruit and/or vegetable consumption & $6(11)$ & $11(24)$ & 0.09 \\
\hline Insufficient physical activity & $4(7)$ & $6(13)$ & 0.35 \\
\hline All risks & $3(6)$ & $4(9)$ & 0.54 \\
\hline \multicolumn{4}{|l|}{ Advised other types of support* } \\
\hline Smoking & $18(33)$ & $14(30)$ & 0.76 \\
\hline Insufficient fruit and/or vegetable consumption & $7(13)$ & $10(22)$ & 0.24 \\
\hline Insufficient physical activity & $11(20)$ & $11(24)$ & 0.67 \\
\hline All risks & $4(7)$ & $2(4)$ & 0.52 \\
\hline
\end{tabular}

*Other support included: dietitian, internet websites, physical activity classes and physiotherapist.

AMS, Aboriginal Medical Service; GP, general practitioner; NRT, nicotine replacement therapy.

referral. However, inconsistencies between client and clinician report were also observed. Both measurement approaches have inherent potential bias, and understanding which approach represents reality is difficulty beyond direct observation. ${ }^{68}{ }^{69}$ However, client recall of preventive care may be judged a more important indicator of care delivery, given clients must recall receiving advice in order to prompt health risk behaviour change. ${ }^{67}$ The primary study limitation is the pre-post design, although it was considered appropriate for this preliminary examination of the potential effectiveness of a clinician practice change intervention. Furthermore, due to the lack of research regarding preventive care within substance use treatment settings, evidence for the use of the 2As+Rmodel was derived from general healthcare settings. However, this model may not be the most appropriate model of preventive care for this setting and warrants further investigation. A further limitation is that the study was conducted in one district within Australia and therefore the generalisability of findings to other services is unknown. In addition, the generalisability of the results may be limited by the differences in demographics between the baseline and follow-up clinician and client samples.

To the authors' knowledge this is the first study to evaluate the effectiveness of a multistrategic clinical 
Table 5 Clinician reported attitudes regarding preventive care at follow-up (agree/strongly agree)

\begin{tabular}{|c|c|}
\hline Attitudinal item & n (\%) \\
\hline \multicolumn{2}{|l|}{ Role congruence } \\
\hline $\begin{array}{l}\text { It is part of my role as a community health clinician to provide preventive care to clients regarding their } \\
\text { smoking behaviours. }\end{array}$ & $45(98)$ \\
\hline My manager believes the provision of preventive care is important. & $43(93)$ \\
\hline $\begin{array}{l}\text { It is part of my role as a community health clinician to provide preventive care to clients regarding their } \\
\text { physical activity levels. }\end{array}$ & $39(85)$ \\
\hline $\begin{array}{l}\text { It is part of my role as a community health clinician to provide preventive care to clients regarding their fruit } \\
\text { and vegetable consumption. }\end{array}$ & $37(80)$ \\
\hline Addressing health risk behaviours with clients does not jeopardise my relationship with the client. ${ }^{*}$ & $36(78)$ \\
\hline Providing preventive care for health risk behaviours leaves me time to undertake acute care of the client.* & $30(65)$ \\
\hline \multicolumn{2}{|l|}{ Self-efficacy } \\
\hline I have the knowledge and skills to provide preventive care to clients regarding all health risk behaviours. & $46(100)$ \\
\hline I feel confident to talk with clients about all their health risk behaviours. & $45(97)$ \\
\hline There are services I can refer my clients to that provide support to change all their health risk behaviours. & $43(93)$ \\
\hline Clients find it acceptable for me to talk with them about their health risk behaviours. & $37(80)$ \\
\hline Clients will change their health risk behaviours because of the care I can provide them. & $26(56)$ \\
\hline \multicolumn{2}{|l|}{ Perceived client interest } \\
\hline Clients I see are not generally too old to benefit from changing their health risk behaviours. & $46(100)$ \\
\hline Clients I see are interested in changing their health risk behaviours. ${ }^{*}$ & $18(39)$ \\
\hline
\end{tabular}

*Item originally worded as a negative statement and has been reversed.

practice intervention on the provision of preventive care to community-based substance use clients for multiple health risk behaviours. The outcomes of this pilot study can be used to inform future, more rigorously designed, interventions. Future interventions can be improved by further investigating the barriers to the provision and uptake of preventive care in substance use settings and selecting strategies to address such barriers.

\section{Author affiliations}

${ }^{1}$ Population Health, Hunter New England Local Health District, Wallsend, New South Wales, Australia

${ }^{2}$ Faculty of Health, The University of Newcastle, Callaghan, New South Wales, Australia

${ }^{3}$ Hunter Medical Research Institute, Newcastle, New South Wales, Australia ${ }^{4}$ Faculty of Science and Information Technology, The University of Newcastle, Callaghan, New South Wales, Australia

${ }^{5}$ Drug and Alcohol Clinical Services, Hunter New England Local Health District, Newcastle, New South Wales, Australia

${ }^{6}$ Centre for Translational Neuroscience and Mental Health, Waratah, New South Wales, Australia

Acknowledgements The authors would like to thank all members of the Preventive Care team, computer-assisted telephone interviewers, Aboriginal Advisory group, electronic medical records team and community substance use treatment service clinicians for their contribution to the project.

Contributors All authors contributed to the study research design and methodology. All authors contributed to, read and approved the final version of this manuscript. DT led the development of the manuscript and the data analysis

Funding Infrastructure support was provided by Hunter Medical Research Institute. Competing interests None decalred.

Patient consent Not required.
Ethics approval Research approval was granted by the Hunter New England (No. 09/06/17/4.03) and the University of Newcastle (No. H-2010-1116) human research ethics committees.

Provenance and peer review Not commissioned; externally peer reviewed.

Data sharing statement Requests for additional unpublished data should be forwarded to danika.tremain@hnehealth.nsw.gov.au.

Open access This is an open access article distributed in accordance with the Creative Commons Attribution Non Commercial (CC BY-NC 4.0) license, which permits others to distribute, remix, adapt, build upon this work non-commercially, and license their derivative works on different terms, provided the original work is properly cited, appropriate credit is given, any changes made indicated, and the use is non-commercial. See: http://creativecommons.org/licenses/by-nc/4.0/.

\section{REFERENCES}

1. Lawrence D, Hancock KJ, Kisely S. The gap in life expectancy from preventable physical illness in psychiatric patients in Western Australia: retrospective analysis of population based registers. BMJ 2013;346:f2539.

2. Chang CK, Hayes RD, Perera G, et al. Life expectancy at birth for people with serious mental illness and other major disorders from a secondary mental health care case register in London. PLoS One 2011;6:e19590.

3. Nordentoft M, Wahlbeck K, Hällgren J, et al. Excess mortality, causes of death and life expectancy in 270,770 patients with recent onset of mental disorders in Denmark, Finland and Sweden. PLoS One 2013;8:e55176.

4. Hurt RD, Offord KP, Croghan IT, et al. Mortality following inpatient addictions treatment. Role of tobacco use in a community-based cohort. J Amer Med Assoc 1996;275:1097-103.

5. De Alba I, Samet JH, Saitz R. Burden of medical illness in drug- and alcohol-dependent persons without primary care. Am J Addict 2004:13:33-45.

6. Stenbacka M, Leifman A, Romelsjö A. Mortality and cause of death among 1705 illicit drug users: a 37 year follow up. Drug Alcohol Rev 2010;29:21-7. 
7. Islam MM, Taylor A, Smyth C, et al. General health of opioid substitution therapy clients. Intern Med J 2013;43:1335-8.

8. World Health Organization. Global status report on noncommunicable diseases 2010. Geneva: World Health Organization, 2011.

9. Australian Institute of Health and Welfare. Living dangerously: Australian's with multiple risk factors for cardiovascular disease. Bulletin 2005. No. 24. Canberra.

10. Prochaska JJ, Delucchi K, Hall SM. A meta-analysis of smoking cessation interventions with individuals in substance abuse treatment or recovery. J Consult Clin Psychol 2004;72:1144-56.

11. Kalman D. Smoking cessation treatment for substance misusers in early recovery: a review of the literature and recommendations for practice. Subst Use Misuse 1998;33:2021-47.

12. Baca CT, Yahne CE. Smoking cessation during substance abuse treatment: what you need to know. J Subst Abuse Treat 2009;36:205-19.

13. Barbadoro P, Ponzio E, Pertosa ME, et al. The effects of educational intervention on nutritional behaviour in alcohol-dependent patients. Alcohol Alcohol 2011;46:77-9.

14. Kelly PJ, Baker AL, Deane FP, et al. Prevalence of smoking and other health risk factors in people attending residential substance abuse treatment. Drug Alcohol Rev 2012;31:638-44.

15. Rice VH, Hartmann-Boyce J, Stead LF. Cochrane Tobacco Addiction Group. Nursing interventions for smoking cessation. Cochrane Database Syst Rev 2013;45:CD001188

16. Rees K, Dyakova M, Ward K, et al. Dietary advice for reducing cardiovascular risk. The Cochrane database of systematic reviews 2013;3:CD002128.

17. Rigotti NA, Munafo MR, Stead LF. Interventions for smoking cessation in hospitalised patients. Cochrane Database Syst Rev 2007;3:CD001837.

18. Hillsdon M, Foster C, Thorogood M. Interventions for promoting physical activity. Cochrane Database Syst Rev 2005;1:CD003180.

19. Glasgow RE, Goldstein MG, Ockene JK, et al. Translating what we have learned into practice. Principles and hypotheses for interventions addressing multiple behaviors in primary care. $A m ~ J$ Prev Med 2004;27(2 Suppl):88-101.

20. The Royal Australian College of General Practitioners. Guidelines for preventive activities in general practice. 8th edn. East Melbourne, 2012.

21. Ministry of Health. New Zealand Smoking Cessation Guidelines. Wellington: Ministry of Health, 2007.

22. Ross LJ, Wilson M, Banks M, et al. Prevalence of malnutrition and nutritional risk factors in patients undergoing alcohol and drug treatment. Nutrition 2012;28(7-8):738-43.

23. Bowman JA, Walsh RA. Smoking intervention within alcohol and other drug treatment services: a selective review with suggestions for practical management. Drug Alcohol Rev 2003;22:73-82.

24. National Institute on Drug Abuse. Principles of Drug Addiction Treatment: A Research-Based Guide. Maryland, US: National Institute on Drug Abuse, 2012

25. New South Wales Health. HNE Health Drug and Alcohol Services Plan 2007-2011. New Lambton: Hunter New England Health, 2007.

26. Fiore MJ CR, Baker T. Treating tobacco use and dependence: 2008 update: In. USDoHaH S, ed. Clinical practice guideline. Rockville, MD: Public Health Service, 2008.

27. Walsh RA, Bowman JA, Tzelepis F, et al. Smoking cessation interventions in Australian drug treatment agencies: a national survey of attitudes and practices. Drug Alcohol Rev 2005;24:235-44.

28. Currie SR, Nesbitt K, Wood C, et al. Survey of smoking cessation services in Canadian addiction programs. J Subst Abuse Treat 2003;24:59-65

29. Tremain D, Freund M, Wye P, et al. Provision of Chronic Disease Preventive Care in Community Substance Use Services: Client and Clinician Report. J Subst Abuse Treat 2016;68:24-30.

30. Rothrauff TC, Eby LT; Public Health Service (u.s.). Substance abuse counselors' implementation of tobacco cessation guidelines. $J$ Psychoactive Drugs 2011;43:6-13.

31. Guydish J, Ziedonis D, Tajima B, et al. Addressing Tobacco Through Organizational Change (ATTOC) in residential addiction treatment settings. Drug Alcohol Depend 2012;121(1-2):30-7.

32. Australian Institute of Health and Welfare. AlHW, ed. Alcohol and other drug treatment services in Australia 2011-12. Canberra, 2013.

33. Australian Institute of Health and Welfare. National Opioid Pharmacotherapy Statistics Annual Data Collection 2012. Canberra: AlHW, 2013.

34. S. A. S. Institute Inc. SAS Software, Version 9.3, 2012.

35. Schroeder SA, Morris CD. Confronting a neglected epidemic: tobacco cessation for persons with mental illnesses and substance abuse problems. Annu Rev Public Health 2010;31:297-314.
36. National Health and Medical Research Council. Australian guidelines to reduce health risk from drinking alcohol. Canberra: Australian Government, 2009.

37. National Health and Medical Research Council. Australian Dietary Guidelines. Canberra: Commonwealth of Australia, 2013.

38. Department of Health and Aged Care. An active way to better health National physical activity guidelines for adults. Canberra: Australian Government, 1999.

39. Ministerial Council on Drug Strategy. National Tobacco Strategy, 2004-2009: The Strategy. Canberra: Commonwealth of Australia, 2004.

40. Stead LF, Perera R, Lancaster T. Telephone counselling for smoking cessation. The Cochrane database of systematic reviews 2006;3:CD002850

41. Eakin EG, Lawler SP, Vandelanotte C, et al. Telephone interventions for physical activity and dietary behavior change: a systematic review. Am J Prev Med 2007;32:419-34.

42. Griffin JL, Segal KS, Nahvi S. Barriers to Telephone Quitline Use Among Methadone-Maintained Smokers. Nicotine Tob Res 2015;17:931-6.

43. Forsetlund L, Bjørndal A, Rashidian A, et al. Continuing education meetings and workshops: effects on professional practice and health care outcomes. Cochrane Database Syst Rev 2009:CD003030.

44. Ivers N, Jamtvedt G, Flottorp S, et al. Audit and feedback: effects on professional practice and healthcare outcomes. Cochrane Database Syst Rev 2012:CD000259.

45. Giguère A, Légaré F, Grimshaw J, et al. Printed educational materials: effects on professional practice and healthcare outcomes. Cochrane Database Syst Rev 2012;10:CD004398.

46. Flodgren G, Parmelli E, Doumit G, et al. Local opinion leaders: effects on professional practice and health care outcomes. Cochrane Database Syst Rev 2011;8:CD000125.

47. Heatherton TF, Kozlowski LT, Frecker RC, et al. The Fagerström Test for Nicotine Dependence: a revision of the Fagerström Tolerance Questionnaire. Br J Addict 1991;86:1119-27.

48. Australian Bureau of Statistics. National Nutrition Survey selected highlights Australia 1995. Canberra: Australian Bureau of Statistics 1997.

49. Marshall AL, Hunt J, Jenkins D. Knowledge of and preferred sources of assistance for physical activity in a sample of urban Indigenous Australians. Int J Behav Nutr Phys Act 2008;5:22

50. Australian Government. Quitline, 1997. http://www.quitnow.gov.au/ (Accessed 17 March, 2014).

51. New South Wales Health. Get Healthy Information and Coaching Service. 2016 http://www.gethealthynsw.com.au/ (Accessed 17 March, 2014).

52. McElwaine KM, Freund M, Campbell EM, et al. Clinician assessment, advice and referral for multiple health risk behaviors: prevalence and predictors of delivery by primary health care nurses and allied health professionals. Patient Educ Couns 2014;94:193-201.

53. Bartlem KM, Bowman JA, Freund M, et al. Care provision to prevent chronic disease by community mental health clinicians. Am J Prev Med 2014:47:762-70.

54. Bartlem K, Bowman J, Ross K, et al. Mental health clinician attitudes to the provision of preventive care for chronic disease risk behaviours and association with care provision. BMC Psychiatry 2016;16:57.

55. Bartlem KM, Bowman J, Freund M, et al. Effectiveness of an intervention in increasing the provision of preventive care by community mental health services: a non-randomized, multiple baseline implementation trial. Implement Sci 2016;11:1-12.

56. Tremain $\mathrm{D}$, Freund $\mathrm{M}$, Wolfenden $\mathrm{L}$, et al. Modifiable health risk behaviours and attitudes towards behaviour change of clients attending community-based substance use treatment services. Drug Alcohol Rev 2017;36.

57. Australian Bureau of Statistics. ABC, ed. SEIFA: Socio-Economic Indexes for Areas. Canberra: ABS, 2008.

58. Department of Health and Aged Care. Measuring remoteness: Accessibility/Remoteness Index of Australia (ARIA). Canberra: Australian Government, 2001.

59. Freund M, Campbell E, Paul C, et al. Smoking care provision in smoke-free hospitals in Australia. Prev Med 2005;41:151-8.

60. Australian Institute of Health and Welfare. Australian Burden of Disease Study: Impact and causes of illness and death in Australia 2011: In. Australian Burden of Disease Study. Canberra: Australian Institute of Health and Welfare, 2016.

61. Australian Institute of Health and Welfare. Australia's Health 2012: In. Australia's health no. 13. Canberra: AlHW, 2012.

62. Winzenberg T, Reid P, Shaw K. Assessing physical activity in general practice: a disconnect between clinical practice and public health? Br J Gen Pract 2009;59:e359-e367. 
63. Wilson AJ, Bonevski B, Dunlop A, et al. 'The lesser of two evils': A qualitative study of staff and client experiences and beliefs about addressing tobacco in addiction treatment settings. Drug Alcohol Rev 2016;35:92-101.

64. Mason R, O'Rinn SE. Co-occurring intimate partner violence, mental health, and substance use problems: a scoping review. Glob Health Action 2014;7:24815.

65. Thomas LH, McColl E, Cullum N, et al. Effect of clinical guidelines in nursing, midwifery, and the therapies: a systematic review of evaluations. Qual Health Care 1998;7:183-91.

66. Conroy MB, Majchrzak NE, Silverman CB, et al. Measuring provider adherence to tobacco treatment guidelines: a comparison of electronic medical record review, patient survey, and provider survey. Nicotine Tob Res 2005;7 Suppl 1(Suppl 1):S35-43.

67. Olsen Y, Alford DP, Horton NJ, et al. Addressing smoking cessation in methadone programs. J Addict Dis 2005;24:33-48.

68. Ward J, Sanson-Fisher R. Accuracy of patient recall of opportunistic smoking cessation advice in general practice. Tob Control 1996;5:110-3.

69. Nicholson JM, Hennrikus DJ, Lando HA, et al. Patient recall versus physician documentation in report of smoking cessation counselling performed in the inpatient setting. Tob Control 2000;9:382-8. 